\title{
Therapeutic Confirmatory Study
}

National Cancer Institute

\section{Source}

National Cancer Institute. Therapeutic Confirmatory Study. NCI Thesaurus. Code C39537.

A clinical study that demonstrates or confirms therapy efficacy, establish regimen safety profile and dose-response relationship. The Confirmatory Study provides basis for assessing the risk-benefit relationship to support therapy licensing. 